\title{
Public Health and Human Right Challenges of Syrian Refugees and Immigrants with Precarious Status
}

\author{
Serdar Aydin ${ }^{1}$, Mustafa Z. Younis ${ }^{2 *}$, Orhan Kocak ${ }^{3}$ \\ ${ }^{1}$ University of South Carolina, Arnold School of Public Health, Health Services and Policy Management, USA \\ ${ }_{2}^{2}$ Jackson State University, 1400 John R. Lynch St, Jackson, MS 39217, USA \\ ${ }^{3}$ Istanbul University, Faculty of Health Sciences, Department of Social Work, TURKEY
}

*Corresponding Author: younis99@gmail.com

Citation: Aydin, S., Younis, M. Z. and Kocak, O. (2019). Public Health and Human Right Challenges of Syrian Refugees and Immigrants with Precarious Status. European Journal of Environment and Public Health, 3(1), em0022. https://doi.org/10.20897/ ejeph/3946

Published: July 11, 2019

\begin{abstract}
Civil unrest in Syria that started in March 2011 has resulted in about five million refugees in neighboring countries - many suffering from physical and mental illnesses due to the environment and pathogens, as well as human rights violence and abuse (UNICEF, 2017). The social, economic, and health costs of the conflict have disproportionately affected women and children, who have - typically been targeted in wartime for violence, abuse, and trafficking into forced labor and sex slavery. The objective of this study is to evaluate what many women and children have experienced, given the complexity of the Syria crisis and its pertinent extreme violence and uncertainty. Women and girls experience high levels of trauma, ranging from severe emotional disorder (psychosis, severe depression, post-traumatic stress disorder (PTSD), severely disabling anxiety, etc.), mild or moderate disorders, and mild or moderate depression and anxiety, among other psychiatric disorders, along with normal distress and other psychological reactions. Those victims of potentially traumatic events are left with the long term effects of clinically relevant PTSD symptoms in addition to stigma and shame (Dadzie, 2017). The goal of this study is to provide the appropriate framework and directions for governments, and public health providers about the necessary interventions and services for those refugees. Such treatments are essential given the high level of physical and mental risk which require early treatment for recovery.
\end{abstract}

Keywords: public health, refugees, Syria, human rights

\section{INTRODUCTION}

Migratory regulations and policies have converged on trying to better control the movement of foreigners across territorial borders. Handling the influx of immigrants has become a burning issue in Western countries, despite the fact that refugees are often forced to escape regions or countries because of events beyond their control, including civil and international war, genocide, military dictatorship, and gross violations of human rights. The violence associated with being forced from one's home country often results in the suffering of individuals and social trauma that disrupts relationships (Rousseau et al., 2008) and affects health status of those affected.

Healthcare professionals working in primary care with migrant and refugee populations are alarmed. According to a study conducted in the US, lack of access to healthcare is directly associated with increased mortality (Wilper et al., 2009). A survey led with healthcare professionals and individuals working in community organizations found out that both healthcare workers and community organization workers alike noted that the burden of finding 
appropriate healthcare for migrants with undocumented status falls disproportionately on those few organizations willing to fight for the latter's rights.

The growing number of immigrants and refugees in the world present enormous challenges to public health practice. Barriers include difficulties in financing their care, cross-cultural communication, and limited cultural awareness on the part of provider (Burgess, 2004).

Refugees and immigrants may have difficulty in building a trust in physicians and western medicine due to the absence of linguistically and culturally accessible care. The miscommunication can cause many errors between patient-provider including possible misdiagnosis. Medical history, current needs, and personal health practices and beliefs are supposed to be known to avoid patients' noncompliance due to incomprehension of instructions, and patients' inappropriate usage of medical services. Feelings of alienation and mistrust often results in patients not seeking medical care. Cultural sensitivity plays a crucial role in medical treatment; therefore, healthcare providers must consider the cultural factors during the all process including; taking a medical history and physical exam, inquiring about traditional treatments practiced, and assessing care needs. National mandates and standards have been developed to eliminate the difficulty refugees face, but the most immediate and necessary need is that is of language interpretation. The national standards of Culturally and Linguistically Appropriate Services in Healthcare (CLAS) aim to reduce cultural and linguistic obstacles to treatment through the following requirements; (1) Language-assistance services should be provided at no cost to the patient, (2)verbal and written notice informing patients of their right to receive language assistance should be provided, (3)unless requested by the patient, family members or friends should not serve as translators, (4) patient-related material and signage must be provided in the commonly encountered patient language group (Burgess, 2004).

Sexual violence is a major concern for Syrian women and girls. A recent study showed that around $31 \%$ of Syrian refugee women have been exposed to conflict related violence and $3 \%$ exposure to non-partner sexual violence (Doedens, 2013). Sexual violence is highly associated with several medical and mental health problems, including depression, PTSD and increased suicidal risk (Joiner et al., 2007).

The most common medical conditions face Syrian refugees include, skin diseases, digestive system diseases, respiratory diseases, traumatic related disorders and other mental disorders, malnutrition and other infectious diseases (El-Khatib et al., 2013). Moreover, they also show high rate in psychiatric disorders, including Post Traumatic Stress Disorder, Mood and Anxiety Disorders. Children are the most vulnerable group in the refugee population. Children are more vulnerable to medical disorders and infections, they may experience loss of one or more of primary care givers, and they may be exposed to physical and sexual abuse.

Communicable diseases are one of the major challenges presented in the Syrian refugees. Syria reported polio outbreak after a 15 year of a polio-free period (Ozaras et al., 2016). Tuberculosis, were reported to be on one of the most common infectious disorders among Syrian refugees. Tuberculosis infection rate ranges between 5-43 in every 100.000 people, with increased incidents of multi-drug resistant cases (Centers for Disease Control and Prevention (CDC), 2017). Lack of access to medical care, limitation to appropriate treatment and poor living conditions may result in an increased infectious disease rate. Syrian refugees may have received vaccination prior to the civil war or at the host country. However, gaps in immunization, especially for young children were reported (Centers for Disease Control and Prevention (CDC), 2017).

Early forced marriage is an increasing problem among Syrian girls who immigrated to Syrian neighbor countries. Some Syrian families believe that child marriage may provide their daughters protection from physical and sexual violence in refugee camps, and will alleviate poverty (Save the Children, 2017; USAID, 2014)However, several studies showed that childhood forced marriage is associated with increased rates of early pregnancy, maternal mortality and other obstetric complications. Early marriage also often results in abbreviated opportunities for education, which results, in the long term, in lower socioeconomic status (USAID, 2014).

An education model has been argued and found to be successful in conveying health, wellness, and prevention information, including healthcare access issues faced by the refuges. Resettlement agency staff and other community resources are playing a key role by providing medical access information in small group settings through a "house party" concept, where clients are recruited to "host" a party with their friends. Guests are actively engaged in the commination and sharing of information that directly affects interaction and strengthening of the client-provider relationship (Burgess, 2004).

Turkey is the country that welcomed all the Syrian refugees fleeing from the civil war and serves as a good model to protect the refugees' right to access healthcare services unlike the actions of many countries. Turkey has selected a morality-centered approach versus a security-center approach for its Syrian refugees (Aras and Mencutek, 2015). The country has adopted an unconditional 'open door policy'. A policy enacted to grant the refugees a temporary protection status provides the Syrians with the right to have temporary asylum. The regulation proves a legal status giving some social rights such as an identity card and social supports. Despite the fact that the refugee crisis is an international responsibility, Turkey carried the lion's share of the crisis and implemented polices that 
went well beyond hospitality. Such policies include housing, employment, education and health (personal and public health) (Kirişci, 2014).

The refugees living in camps were easy to locate in order to provide immunizations and other health care and social services. However, the rest of refugees who are living off camps, for various reasons, such as availability of lands to build news camps, were harder to reach. Such situations put pressure on health care workers to treat infectious diseases, chronic diseases, and to provide immunizations and mental health services.

The refugee might have common health and social needs, however it is productive to categorize the health needs for the refugees into usable categories, such as children, women (include pregnancy and child care, the elderly and aging, and others population. Each category has its unique and addition circumstance and needs.

Conclusion

The crisis in Syria spelled over neighboring countries and Europe. Turkey, Lebanon and Jordan had the large share of refugees in comparison to the European countries.

Turkey with historical relationship to Syria, welcomed the refugees and provided them with possible housing, healthcare and assistant. However, the long term solution to such refugee crisis is the political stability in Syria and the region. Turkey and other countries will have limited resources in handle such instability in long term.

\section{REFERENCES}

Aras, N. E. G. and Mencutek, Z. S. (2015). The international migration and foreign policy nexus: the case of Syrian refugee crisis and Turkey. Migration Letters, 12(3), 193.

Burgess, A. (2004). Health challenges for refugees and immigrants. Refugee Reports, 25(2), 1-3.

Centers for Disease Control and Prevention (CDC). (2017, 01/25/2017). Refugee Health Profiles. Available at: https://www.cdc.gov/immigrantrefugeehealth/profiles/index.html

Dadzie, G. M. (2017). Healthcare Accessibility for Syrian Refugees: Understanding Trends, Host Countries' Responses and Impacts on Refugees' Health. State University of New York.

Doedens, W. et al. (2013). Reproductive Health Services for Syrian Refugees in Zaatri Refugee Camp and Irbid City, Jordan.

El-Khatib, Z., Scales, D., Vearey, J. and Forsberg, B. C. (2013). Syrian refugees, between rocky crisis in Syria and hard inaccessibility to healthcare services in Lebanon and Jordan. Confl Health, 7(1), 18. https://doi.org/10.1186/1752-1505-7-18

Joiner, T. E., Sachs-Ericsson, N. J., Wingate, L. R., Brown, J. S., Anestis, M. D. and Selby, E. A. (2007). Childhood physical and sexual abuse and lifetime number of suicide attempts: A persistent and theoretically important relationship. Behaviour research and therapy, 45(3), 539-547. https://doi.org/10.1016/j.brat.2006.04.007

Kirişci, K. (2014). Syrian refugees and Turkey's challenges: Going beyond hospitality: Brookings Washington, DC.

Ozaras, R., Leblebicioglu, H., Sunbul, M., Tabak, F., Balkan, I. I., Yemisen, M., ..., Ozturk, R. (2016). The Syrian conflict and infectious diseases. Expert review of anti-infective therapy, 14(6), 547-555. https://doi.org/10.1080/14787210.2016.1177457

Rousseau, C., Ter Kuile, S., Muňoz, M., Nadeau, L., Ouimet, M.-J., Kirmayer, L. and Crépeau, F. (2008). Health care access for refugees and immigrants with precarious status: public health and human right challenges.

Save the Children. (2017). Available at: https:/ /www.savethechildren.org.uk

UNICEF. (2017). UNICEF Syria Crisis Situation Report August 2017 - Humanitarian Results. Available at: https:// reliefweb.int/report/syrian-arab-republic/unicef-syria-crisis-situation-report-august-2017humanitarian-results

USAID. (2014). Child, Early, and Forced Marriage: United States Government's Response. Available at: https:/ / www.usaid.gov/news-information/fact-sheets/child-early-and-forced-marriage-usg-response

Wilper, A. P., Woolhandler, S., Lasser, K. E., McCormick, D., Bor, D. H. and Himmelstein, D. U. (2009). Health insurance and mortality in US adults. American Journal of Public Health, 99(12), 2289-2295. https://doi.org/10.2105/AJPH.2008.157685 